\title{
Optimal management when unsuspected N2 nodal disease is identified during thoracotomy for lung cancer: Cost-effectiveness analysis
}

Mark K. Ferguson, MD

From the Department of Surgery, The University of Chicago, Chicago, Ill.

Read at the Eighty-third Annual Meeting of The American Association for Thoracic Surgery, Boston, Mass, May 4-7, 2003.

Received for publication April 21, 2003; revisions received July 24, 2003; accepted for publication July 30, 2003

Address for reprints: Mark K. Ferguson, MD, Department of Surgery, The University of Chicago, 5841 S. Maryland Avenue MC5035, Chicago, IL 60637 (E-mail: mferguso@ surgery.bsd.uchicago.edu)

J Thorac Cardiovasc Surg 2003;126: $1935-42$

Copyright () 2003 by The American Association for Thoracic Surgery

$0022-5223 / 2003 \$ 30.00+0$

doi:10.1016/j.jtcvs.2003.07.031
Objectives: Whether to proceed with lung resection when N2 nodal disease is identified at the time of thoracotomy for lung cancer is controversial. A decision analysis model was developed to address this question.

Methods: A meta-analysis was performed on data from reports published between 1990 and 2002 evaluating survival for (1) patients who were treated by initial resection for clinically unsuspected N2 nodal disease (initial resection) and (2) survival for patients undergoing resection after neoadjuvant therapy for $\mathrm{N} 2$ nodal disease (no initial resection). Hospital cost data for surgery were derived from our institution, and cost data for chemotherapy and radiation therapy were obtained from current literature. A decision model was developed to compare initial resection to no initial resection from the perspective of the medical center using survival, quality-adjusted life years survival, and cost-effectiveness as outcomes.

Results: The no initial resection option provided better median survival ( 2.1 versus 1.7 years), quality-adjusted life years (1.8 versus 1.3 ), and cost-effectiveness, with an incremental cost-effectiveness ratio of $\$ 17,119$ /quality-adjusted life year. Outcomes were influenced by survival estimates for each treatment option.

Conclusions: When N2 nodal disease is discovered during thoracotomy, the approach of delaying resection until after neoadjuvant therapy provides the best survival and is more cost-effective. This is likely due to the beneficial effects of neoadjuvant therapy and the exclusion of patients with more aggressive disease from the surgical candidate pool.

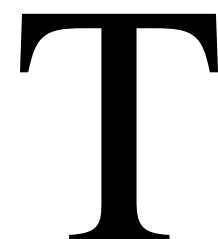

he appropriate management of patients with non-small cell lung cancer (NSCLC) metastatic to N2 lymph nodes is controversial. Results of 2 randomized trials indicate that neoadjuvant therapy followed by resection in selected patients improves long-term and disease-free survival compared with resection alone. ${ }^{1,2}$ These findings suggest that in patients in whom there is a suspicion of $\mathrm{N} 2$ nodal disease based on clinical findings, an evaluation such as mediastinoscopy, thoracoscopy, or positron emission tomography (PET) is appropriate to document N2 nodal status. If $\mathrm{N} 2$ nodal disease is identified prior to thoracotomy, such patients should undergo neoadjuvant therapy possibly followed by resection.

A more difficult problem is appropriate management of patients in whom $\mathrm{N} 2$ nodal disease is not suspected prior to thoracotomy but is identified intraoperatively, prior to formal lung resection. Options for management include proceeding with lung resection or aborting the resection to permit neoadjuvant therapy possibly followed by subsequent resection. Most surgeons favor proceeding with lung resection in this situation, theorizing that the patient has already been exposed to the major risks associated with surgical care of lung cancer. However, there are no trials that have compared outcomes of these 2 choices. 
TABLE 1. Values for variables used in decision model

\begin{tabular}{|c|c|c|c|}
\hline Variable & Value & Range & References \\
\hline \multicolumn{4}{|l|}{ Initial resection group } \\
\hline Operative mortality & 0.03 & $0.01-0.05$ & $4-13$ \\
\hline Likelihood of postoperative RT & 0.25 & $0.15-0.35$ & $4-13$ \\
\hline Likelihood of postoperative CRT & 0.5 & $0.4-0.6$ & $4-13$ \\
\hline Survival-resection only (years) & 1.8 & $1.2-2.4$ & 4-13 \\
\hline Survival-resection and adjuvant therapy (years) & 1.8 & $1.2-2.4$ & $14-16$ \\
\hline \multicolumn{4}{|l|}{ No initial resection group } \\
\hline Operative mortality for exploration & 0.005 & $0.002-0.01$ & 17 \\
\hline Operative mortality for subsequent resection & 0.05 & $0.03-0.07$ & $13,18-35$ \\
\hline Likelihood of subsequent resection & 0.7 & $0.5-0.9$ & $13,18-35$ \\
\hline Survival-neoadjuvant therapy and resection (years) & 2.6 & $2.0-3.2$ & $1,2,13,18-23,26-35$ \\
\hline Survival—neoadjuvant therapy only (years) & 1.0 & $0.8-1.2$ & $2,22,29,35-37$ \\
\hline \multicolumn{4}{|l|}{ Other global variables } \\
\hline Cost RT (\$) & 2744 & $2000-3500$ & 38,39 \\
\hline Cost CRT (\$) & 6932 & $5223-8652$ & $38-45$ \\
\hline Cost resection (\$) & 14,214 & $13,178-14,800$ & Study data \\
\hline Cost surgical exploration (\$) & 8900 & $7100-10,700$ & Study data \\
\hline Cost operative mortality $(\$)$ & 36,787 & $25,000-48,574$ & Study data \\
\hline Quality-of-life during postoperative recovery & 0.75 & $0.6-0.9$ & 46,47 \\
\hline Quality-of-life during RT & 0.7 & $0.5-0.9$ & 38,39 \\
\hline Quality-of-life during neoadjuvant or adjuvant CRT & 0.65 & $0.5-0.8$ & $38-45$ \\
\hline Quality-of-life after all therapy completed & 0.85 & $0.75-0.95$ & $46-49$ \\
\hline
\end{tabular}

$R T$, Radiation therapy; $C R T$, chemoradiotherapy.

Analyzing the potential benefits of competing choices for surgical therapy in the absence of reliable information regarding the relative utility of each option is difficult. Decision analysis techniques have recently been used to explore such situations, particularly those in which the performance of randomized clinical trials aimed at definitively answering such questions is impractical. A decision analysis model was developed to explore whether initial resection or neoadjuvant therapy followed by resection is most effective in patients with clinically unsuspected N2 nodal disease discovered at the time of thoracotomy for NSCLC.

\section{Methods}

A Medline search of reports published in English from 1990 to 2002 using the combined search criteria ["lung resection" and "lung neoplasm"] and ["stage III" or "stage IIIa" or "mediastinal adenopathy" or "N2"] using the current staging system was performed and yielded 457 articles. ${ }^{3}$ One-hundred thirteen abstracts were reviewed and a related article search was performed on appropriate abstracts. Articles that were selected satisfied these criteria: at least 25 patients in each surgical candidate group; median survival was stated or calculable for N2 patients; and operative mortality was reported or calculable for $\mathrm{N} 2$ patients. Data related to malignancies other than NSCLC and information for patients with other than stage IIIa disease were discarded. Data were abstracted for patients who underwent neoadjuvant chemotherapy or chemoradiotherapy as part of prospective trials for clinically or histologically documented N2 disease, whereas data were abstracted for patients who underwent initial resection and who had no clinical evidence for pathologic N2 disease.
Meta-analyses of the resultant data were performed including calculation of weighted mean survival for the surgical groups. Estimates for other parameters were derived from studies ${ }^{4-49}$ published during the same time interval (Table 1). Quality-adjusted life years (QALY) was calculated by multiplying median survival (expressed in years) by a quality-of-life utility scale that was estimated from recent reports and in which death had a value of 0 and full health had a value of 1 (Table 1). Cost information for surgery was obtained from data collected on 100 patients who underwent thoracotomy for lung resection at the University of Chicago from 1998 to 2001 under a protocol that was approved by the Institutional Review Board and for which specific patient consent was not required. Cost information for chemotherapy and radiation therapy was obtained from current literature (Table 1). In all cases only direct cost information was used, and all costs were normalized to 2002 US dollars based on the Consumer Price Index. Ranges for variables were calculated based on $95 \%$ confidence intervals when available or were estimated when necessary.

A decision analysis model was created using a dichotomous choice between resection and no initial resection to explore the 2 available options for managing patients with NSCLC accompanied by clinically unsuspected $\mathrm{N} 2$ nodal disease discovered at the time of thoracotomy (Figure 1). It was assumed that patients undergoing neoadjuvant therapy received 2 cycles of chemotherapy with 2 agents and 50-Gy radiation therapy. Periods of decreased quality of life were assumed to be 0.1 years for postoperative patients who were to receive neoadjuvant or adjuvant therapy, 0.2 years for postoperative patients who did not receive neoadjuvant or adjuvant therapy, and 0.2 years for administration of neoadjuvant or adjuvant therapy. No adjustment was made for quality of life at end of life. Outcomes (rewards) were analyzed from the perspective of 


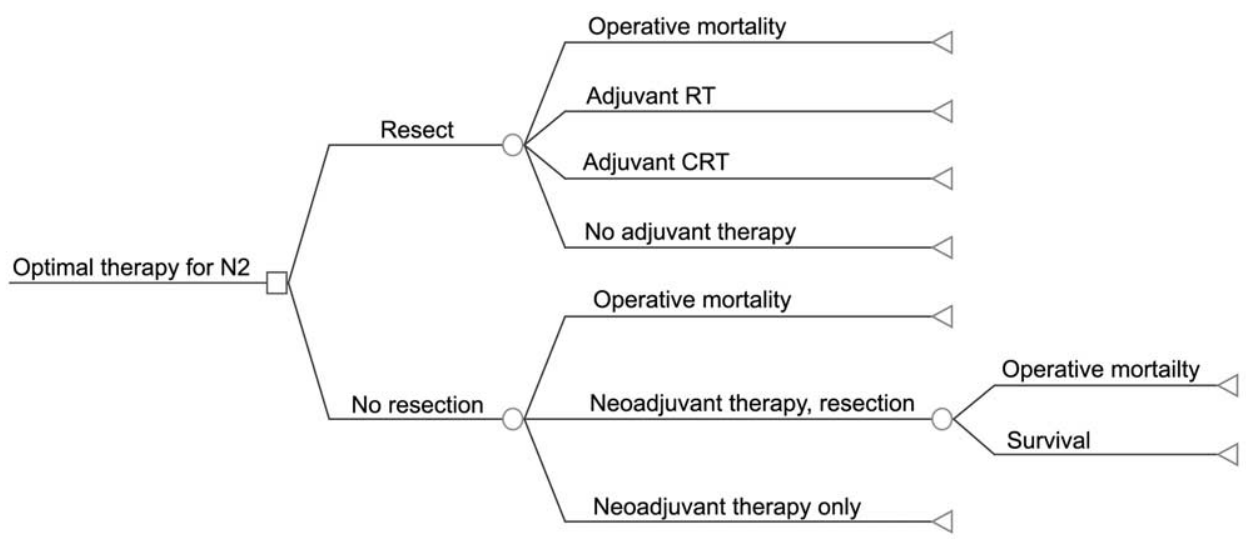

Figure 1. Decision model for assessing optimal therapy for non-small cell lung cancer with N2 nodal disease discovered at the time of thoracotomy. The square represents the decision node, the circles are chance nodes, and the triangles are terminal nodes. $R T$, radiotherapy; CRT, chemoradiotherapy.

the medical center and included median survival, QALY, and cost-effectiveness. The incremental cost-effectiveness ratio (ICER) was determined and was compared with a willingness-topay threshold of $\$ 50,000 / \mathrm{Q} A L Y$. One-way sensitivity analyses were performed on all variables, and 2-way sensitivity analyses were performed on selected variables. Statistical analyses were performed with Minitab 12.1 (Minitab, Inc, State College, Pa) and Data Pro (release 7.0; TreeAge Software, Inc, Williamstown, Mass) was used for all decision analyses.

\section{Results}

Data were obtained on 1046 patients without clinical evidence of N2 nodal disease who underwent resection without neoadjuvant therapy and on 775 patients who were found to have $\mathrm{N} 2$ disease prior to resection and who underwent neoadjuvant chemotherapy or chemoradiotherapy alone (175 patients) or followed by resection (600 patients). Using median survival as the reward, the decision model favored no initial resection (2.1 years versus 1.7 years). Using QALY as the reward, the decision model favored no initial resection (1.8 QALY versus 1.3 QALY). When cost-effectiveness was analyzed, the no initial resection option was more costly but also provided greater QALY $(\$ 27,000 / 1.8$ QALY versus \$19,000/1.3 QALY); neither management option was dominant. The ICER was \$17,119/QALY, which is well below the standard willingness-to-pay threshold of \$50,000/QALY (Table 2). Based on 1-way sensitivity analyses, the model was influenced by survival estimates, both for the initial resection followed by adjuvant therapy group (threshold 2.28 QALY; Figure 2) and for the no initial resection group (threshold 2.07 QALY; Figure 3). A 2-way sensitivity analysis for these variables demonstrated the no initial resection option to provide greater value (Figure 4).

\section{Discussion}

Optimal management of patients with NSCLC who have clinically negative $\mathrm{N} 2$ nodes but who are discovered to have
N2 nodal disease at the time of thoracotomy is controversial. Most surgeons recommend proceeding with resection in otherwise healthy patients who have relatively favorable findings, such as a single N2 nodal level involved, absence of capsular invasion, and a T1 or T2 primary tumor. It has been suggested that resection is justified in such patients, "who have already necessarily incurred the morbidity and mortality of thoracotomy." patients appear to have favorable long-term survival, the overall outcomes after surgery for $\mathrm{N} 2$ nodal disease are far from satisfactory. In addition, important morbidity after exploratory thoracotomy without resection is rare, mortality is negligible, and long-term outcomes are not appreciably affected. $^{17,50}$

No information from randomized trials is available regarding the respective outcomes for these choices, and such a trial is unlikely to be performed. Nevertheless, the management question is an important one, if only because the incidence of clinically unsuspected N2 nodal involvement is as high as $15 \%$ to $25 \%$ in patients undergoing thoracotomy for resection. ${ }^{8,51}$ Favorable survival may be related to a number of anatomic factors, such as the specific nodal stations involved, the number of involved nodes, and whether the disease is gross or microscopic. However, it is likely that the tumor biology in each patient is the most important determinant of long-term outcome. Delaying resection to enable assessment of tumor biology, in part by evaluating the response of the tumor to neoadjuvant therapy, may help select patients in whom resection is most appropriate.

Medical applications of decision analysis techniques were originally developed in the 1970 s to provide insight into the management of individual patients. They have recently been found useful for developing policies about groups of patients by providing information on which of 2 or more management strategies has the most value. ${ }^{52}$ These 


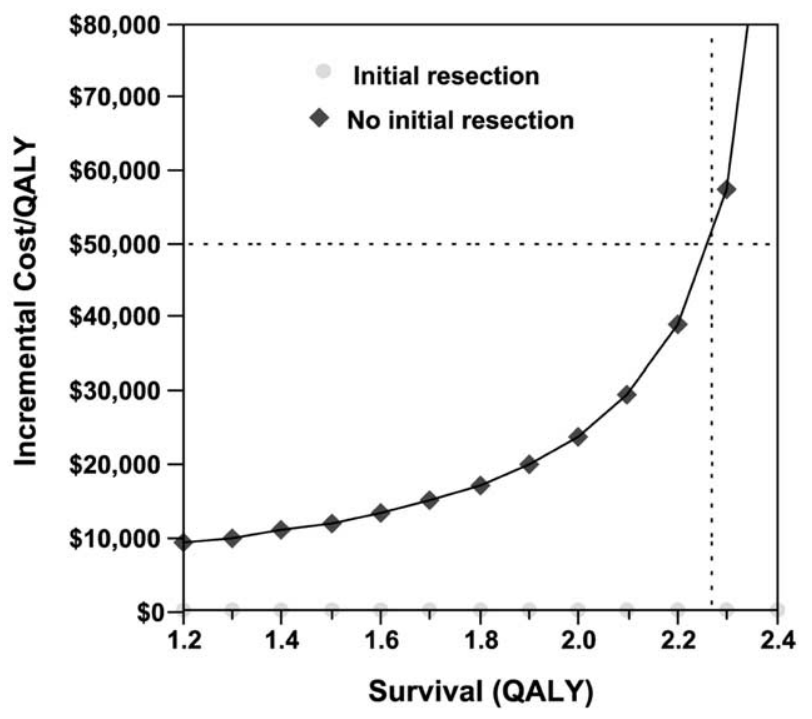

Figure 2. One-way sensitivity analysis for survival after initial surgery followed by adjuvant therapy. The possible outcomes are compared with the incremental cost/QALY of the no initial resection option. The value for survival above which the incremental cost/QALY of the no initial resection option exceeds the willingness-to-pay threshold of $\$ 50,000 / 0 A L Y$ (horizontal dotted line) is 2.28 OALY (vertical dotted line).

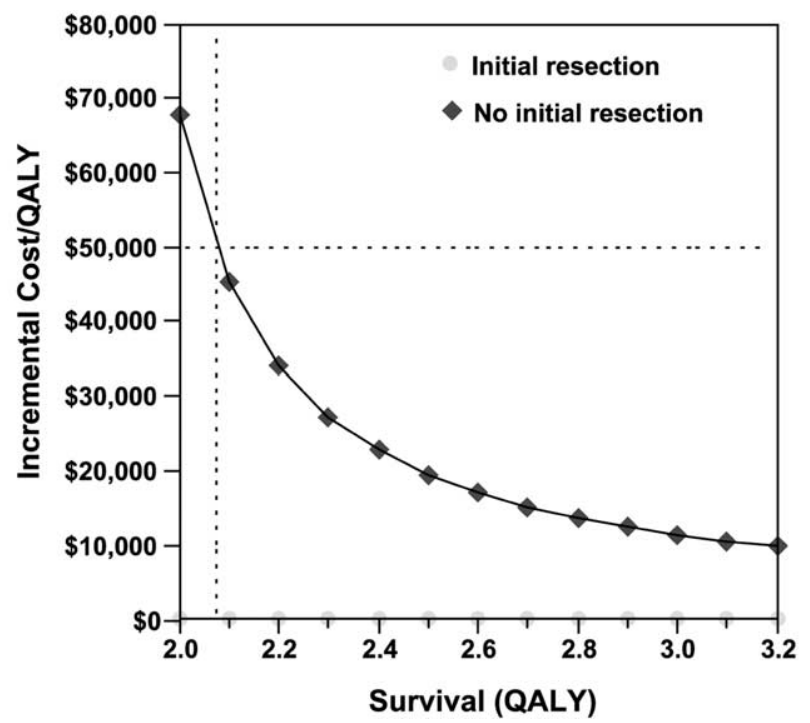

Figure 3. One-way sensitivity analysis for survival after no initial resection followed by neoadjuvant therapy and resection. The possible outcomes are compared with the incremental cost/QALY of the no initial resection option. The value for survival below which the incremental cost/QALY of the no initial resection option exceeds the willingness-to-pay threshold of $\$ 50,000 / 0 A L Y$ (horizontal dotted line) is 2.07 OALY (vertical dotted line).

TABLE 2. Incremental cost-effectiveness ratio (ICER)

\begin{tabular}{|c|c|c|c|c|c|c|}
\hline Choice & $\begin{array}{c}\text { Cost } \\
\text { (\$) }\end{array}$ & $\begin{array}{l}\text { Incremental } \\
\text { cost }(\$)\end{array}$ & $\begin{array}{l}\text { Effectiveness } \\
\text { (OALY) }\end{array}$ & $\begin{array}{l}\text { Incremental effectiveness } \\
\text { (OALY) }\end{array}$ & Cost/effectiveness & ICER \\
\hline Initial resection & 19,000 & & 1.34 & & $\$ 14,193 /$ OALY & \\
\hline $\begin{array}{l}\text { Neoadjuvant therapy followed } \\
\text { by resection }\end{array}$ & 27,000 & 8,000 & 1.80 & 0.45 & $\$ 14,933 / 0 A L Y$ & $\$ 17,119 /$ QALY \\
\hline
\end{tabular}

ICER, Incremental cost-effectiveness ratio; $Q A L Y$, quality-adjusted life years.

"thought experiments" may be based on real data or may rely entirely on hypothetical values gleaned from clinical experience. In either situation, these exercises are useful in situations in which real experiments involving patients are impractical or impossible to conduct.

The reports selected from which data were abstracted for inclusion in this decision model favored the choice of initial resection. Patients who underwent initial resection had no clinical evidence for $\mathrm{N} 2$ disease prior to thoracotomy. In contrast, patients who had no initial resection often had clinical evidence for $\mathrm{N} 2$ nodal disease, a characteristic that has been associated with poor long-term survival. Similarly, operative mortality selected for the initial resection arm of the decision model was lower than that selected for the no initial resection arm, although favorable postoperative outcomes have been reported for patients after neoadjuvant therapy. Despite the fact that the patient characteristics in the sampled reports appeared to favor the choice of initial resection, the decision analysis favored the no initial resection arm for each of the outcomes analyzed.

The primary reason why postponed resection had an advantage in this model was the survival advantage evident in the literature for patients who underwent neoadjuvant therapy compared with patients who underwent initial resection for $\mathrm{N} 2$ nodal disease. It is possible that the difference in calculated survival is spurious. Patients treated with neoadjuvant therapy were usually part of prospective trials and were subjected to more rigorous preoperative staging than patients who underwent initial resection. This helped ensure that the patients receiving neoadjuvant therapy did not have $\mathrm{N} 3$ disease, which remained a possibility in some patients who had initial resection. However, a survival advantage has been demonstrated in randomized studies for patients with $\mathrm{N} 2$ nodal disease who received neodadjuvant therapy followed by resection compared with resection alone, suggesting that a real benefit is conferred by neoad- 
juvant therapy. ${ }^{1,2}$ In contrast, most published evidence suggests that if multimodality therapy is to be given, it should be done as neoadjuvant therapy followed by surgery. ${ }^{14-16}$

Many approaches to modeling staging and therapy for regionally advanced lung cancer are possible. For example, the routine use of mediastinoscopy may reduce the percentage of patients discovered to have N2 disease at the time of thoracotomy but would not appreciably change the management options at the time of thoracotomy. In addition, endof-life issues are not addressed. These include costs and quality of life (QOL) associated with death owing to recurrent disease and those associated with death resulting from intercurrent disease. No reliable data regarding these issues are available. Finally, the current model does not include an option for postoperative adjuvant chemotherapy, a treatment option that is offered to some patients who complete neoadjuvant therapy but have residual nodal disease at the time of resection. Recent information suggests the possibility that such therapy may improve long-term survival by a few percentage points. ${ }^{53}$ Inclusion of such options would not alter the conclusions of this study because of the large gap between the ICER and the willingness-to-pay threshold.

Estimations of QOL formed an important part of the calculation of incremental cost-effectiveness ratio, upon which the conclusions of this study are based. Both the duration of reduced QOL associated with therapy and the amount of reduction of QOL are insufficiently studied. More is known about the effects of chemotherapy than is known about the effects of radiotherapy or surgery. Fortunately, the results reported for both radiotherapy and for surgery are relatively consistent regarding the amount of reduction in QOL; less is known about the duration of QOL reduction for these treatment modalities.

The ranges of values for QOL were purposely set rather wide to account for the fact that the QOL values were possibly not as reliable as values for other variables. However, given the large discrepancy in long-term survival, the relatively small duration of reduced QOL, and the similar overall QOL for all 3 outcome groups, it would take a considerable and isolated reduction in QOL for the no initial resection group to result in a change in the conclusions of this study.

The results demonstrate that rather than resecting patients who are identified as having N2 nodal disease at the time of initial exploratory thoracotomy, the option of postponing resection and referring patients for neoadjuvant therapy was preferred in this model. This was likely due to the beneficial effects of neoadjuvant therapy and the exclusion of patients with more aggressive disease from the surgical candidate pool. This permitted subsequent resection for selected patients, presumably those who had more favorable tumor biology, and provided the best outcomes in terms of survival and QALY. Most importantly, the cost-effective-

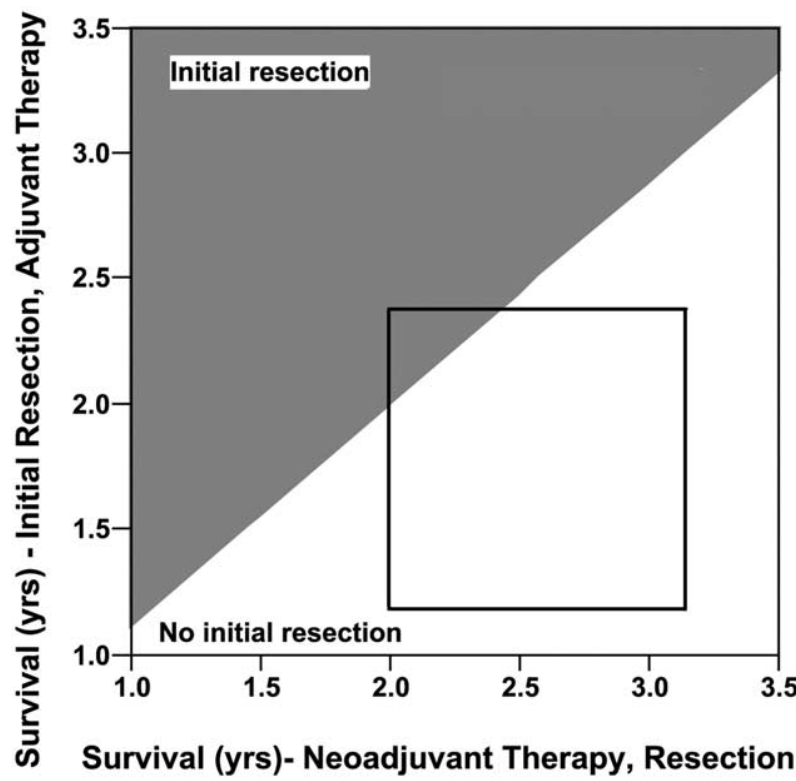

Figure 4. Two-way sensitivity analysis for survival after no initial resection followed by neoadjuvant therapy and resection versus initial resection followed by adjuvant therapy. The shaded region indicates values for which initial resection is optimal, and the open region indicates values for which no initial resection is optimal. The box represents the $95 \%$ confidence intervals for each option, demonstrating that the no initial resection option provides better outcomes for most values in the selected range.

ness analysis yielded an ICER of only \$17,119/QALY, a value that is well within commonly accepted willingnessto-pay thresholds. ${ }^{54}$

The findings of this study will hopefully stimulate physicians who care for lung cancer patients to consider the potential benefits of preoperative and intraoperative staging prior to proceeding with lung resection. Ongoing efforts exploring the relative merits of PET, mediastinoscopy, and endoscopic ultrasonography may help clarify preoperative staging options. Although several reports demonstrate a survival advantage for patients with limited $\mathrm{N} 2$ nodal involvement, accurate determination of the extent of $\mathrm{N} 2$ nodal involvement is often not possible during intraoperative staging due to sampling errors and the limitations of frozen section techniques. As a result, differentiating between favorable and unfavorable $\mathrm{N} 2$ disease intraoperatively may not be possible. The results of the present study suggest that when clinically unsuspected $\mathrm{N} 2$ disease is discovered intraoperatively, delaying resection until after completion of neoadjuvant therapy is beneficial.

\section{References}

1. Rosell R, Gomez-Codina J, Camps C, et al. Preresectional chemotherapy in stage IIIA non-small-cell lung cancer: a 7-year assessment of a randomized controlled trial. Lung Cancer. 1999;26:7-14.

2. Roth JA, Fossella F, Komaki R, et al. A randomized trial comparing 
perioperative chemotherapy and surgery with surgery alone in resectable stage IIIA non-small-cell lung cancer. J Natl Cancer Inst. 1994; 86:673-80.

3. American Joint Committee on Cancer. AJCC staging manual. 6th ed. New York: Springer-Verlag; 2002.

4. Ishida T, Tateishi M, Kaneko S, Sugimachi K. Surgical treatment of patients with nonsmall-cell lung cancer and mediastinal lymph node involvement. J Surg Oncol. 1990;43:161-6.

5. Watanabe Y, Shimizu J, Oda M, et al. Aggressive surgical intervention in N2 non-small cell cancer of the lung. Ann Thorac Surg. 1991;51: 253-61.

6. van Klaveren RJ, Festen J, Otten HJ, Cox AL, de Graaf R, Lacquet LK. Prognosis of unsuspected but completely resectable N2 non-small cell lung cancer. Ann Thorac Surg. 1993;56:300-4.

7. Dalton R, Keller S. Survival following resection of clinically occult N2 non small cell lung cancer. J Cardiovasc Surg (Torino). 1994;35:13-7.

8. Goldstraw P, Mannam GC, Kaplan DK, Michail P. Surgical management of non-small-cell lung cancer with ipsilateral mediastinal node metastasis (N2 disease). J Thorac Cardiovasc Surg. 1994;107:19-27.

9. Miller DL, McManus KG, Allen MS, et al. Results of surgical resection in patients with N2 non-small cell lung cancer. Ann Thorac Surg. 1994;57:1095-101.

10. De Leyn P, Schoonooghe P, Deneffe G, et al. Surgery for non-small cell lung cancer with unsuspected metastasis to ipsilateral mediastinal or subcarinal nodes (N2 disease). Eur J Cardiothorac Surg. 1996;10: 649-54.

11. Nakanishi R, Osaki T, Nakanishi K, et al. Treatment strategy for patients with surgically discovered N2 stage IIIA non-small cell lung cancer. Ann Thorac Surg. 1997;64:342-8.

12. Andre F, Grunenwald D, Pignon JP, et al. Survival of patients with resected N2 non-small-cell lung cancer: evidence for a subclassification and implications. J Clin Oncol. 2000;18:2981-9.

13. Okada M, Tsubota N, Yoshimura M, Miyamoto Y, Matsuoka H. Induction therapy for non-small cell lung cancer with involved mediastinal nodes in multiple stations. Chest. 2000;118:123-8.

14. Ohta M, Tshuchiya R, Shimoyama M, et al. Adjuvant chemotherapy for completely resected stage III non-small-cell lung cancer. J Thorac Cardiovasc Surg. 1993;106:703-8.

15. Debevec M, Bitenc M, Vidmar S, et al. Postoperative radiotherapy for radically resected N2 non-small-cell lung cancer (NSCLC): randomised clinical study 1988-1992. Lung Cancer. 1996;14:99-107.

16. Logan DM, Lochrin CA, Darling G, Eady A, Newman TE, Evans WK. Adjuvant radiotherapy and chemotherapy for stage II or IIIA nonsmall-cell lung cancer after complete resection. Provincial Lung Cancer Disease Site Group. Cancer Prev Control. 1997;1:366-78.

17. Steinbaum SS, Uretzky ID, McAdams HP, Torrington KG, Cohen AJ. Exploratory thoracotomy for nonresectable lung cancer. Chest. 1995; 107:1058-61.

18. Yashar J, Weitberg AB, Glicksman AS, Posner MR, Feng W, Wanebo HJ. Preoperative chemotherapy and radiation therapy for stage IIIa carcinoma of the lung. Ann Thorac Surg. 1992;53:445-8.

19. Pass HI, Pogrebniak HW, Steinberg SM, Mulshine J, Minna J. Randomized trial of neoadjuvant therapy for lung cancer: interim analysis. Ann Thorac Surg. 1992;53:992-8.

20. Reddy S, Lee MS, Bonomi P, et al. Combined modality therapy for stage III non-small cell lung carcinoma: results of treatment and patterns of failure. Int J Radiat Oncol Biol Phys. 1992;24:17-23.

21. Burkes RL, Ginsberg RJ, Shepherd RA, et al. Induction chemotherapy with MVP (mitomycin-C + vindesine + cisplatin) for stage III (T1-2, N2, M0) unresectable non-small cell lung cancer: the Toronto experience. Lung Cancer. 1993;9:377-82.

22. Martini N, Kris MG, Flehinger BJ, et al. Preoperative chemotherapy for stage IIIa (N2) lung cancer: the Sloan-Kettering experience with 136 patients. Ann Thorac Surg. 1993;55:1365-73.

23. Elias AD, Skarin AT, Gonin R, et al. Neoadjuvant treatment of stage IIIA non-small cell lung cancer. Am J Clin Oncol. 1994;17:26-36.

24. Rosell R, Gomez-Codina J, Camps C, et al. A randomized trial comparing preoperative chemotherapy plus surgery with surgery alone in patients with non-small-cell lung cancer. $N$ Engl J Med. 1994;330: 153-8.

25. Roth JA, Atkinson EN, Fossella F, et al. Long-term follow-up of patients enrolled in a randomized trial comparing perioperative chemotherapy and surgery with surgery alone in resectable stage IIIA non-small-cell lung cancer. Lung Cancer. 1998;21:1-6.

26. Chella A, Lucchi M, Ribechini A, et al. Pre-operative chemotherapy for stage IIIa (N2) non-small cell lung cancer. Eur J Surg Oncol. 1995;21:393-7.

27. Darrwish S, Minotti V, Crino L, et al. A phase II trial of combined chemotherapy and surgery in stage IIIA non-small cell lung cancer. Lung Cancer. 1995;12(Suppl 1):S71-8.

28. Rice TW, Adelstein DJ, Koka A, Tefft M, Kirby TJ, Van Kirk MA. Accelerated induction therapy and resection for poor prognosis stage III non-small cell lung cancer. Ann Thorac Surg. 1995;60:586-92.

29. Sugarbaker DJ, Herndon J, Kohman LJ, Krasna MJ, Green MR. Results of cancer and leukemia group B protocol 8935. A multiinstitutional phase II trimodality trial for stage IIIA (N2) non-small-cell lung cancer. Cancer and Leukemia Group B Thoracic Surgery Group. J Thorac Cardiovasc Surg. 1995;109:473-83.

30. Mathisen DJ, Wain JC, Wright C, et al. Assessment of preoperative accelerated radiotherapy and chemotherapy in stage IIIA (N2) nonsmall-cell lung cancer. J Thorac Cardiovasc Surg. 1996;111:123-33.

31. Elias AD, Skarin AT, Leong T, et al. Neoadjuvant therapy for surgically staged IIIA N2 non-small cell lung cancer (NSCLC). Lung Cancer. 1997;17:147-61.

32. Granone P, Margaritora S, Cesario A, Bonatti P, Galetta D, Picciocchi A. Concurrent radio-chemotherapy in N2 non small cell lung cancer: interim analysis. Eur J Cardiothorac Surg. 1997;12:366-71.

33. De Leyn P, Vansteenkiste J, Deneffe G, Van Raemdonck D, Coosemans W, Lerut $\mathrm{T}$. Result of induction chemotherapy followed by surgery in patients with stage IIIA N2 NSCLC: importance of pretreatment mediastinoscopy. Eur J Cardiothorac Surg. 1999;15:608-14.

34. Ahn YC, Park K, Kim DY, et al. Preoperative concurrent chemoradiotherapy for stage IIIA non-small cell lung cancer. Acta Oncol. 2001;20:588-92.

35. Voltolini L, Luzzi L, Ghiribelli C, Paladini P, Di Bisceglie M, Gotti G. Results of induction chemotherapy followed by surgical resection in patients with stage IIIA (N2) non-small cell lung cancer: the importance of the nodal down-staging after chemotherapy. Eur J Cardiothorac Surg. 2001;20:1106-12.

36. Kirn DH, Lynch TJ, Mentzer SJ, et al. Multimodality therapy of patients with stage IIIA, N2 non-small-cell lung cancer. Impact of preoperative chemotherapy on resectability and downstaging. J Thorac Cardiovasc Surg. 1993;106:696-702.

37. Maggi G, Casadio C, Cianci R, et al. Preoperative concurrent radiation and cisplatinum continuous infusion in IIIa (N2) non small cell lung cancer. A pilot study. J Cardiovasc Surg. 1994;35:341-6.

38. Earle C, Coyle D, Smith A, Agboola O, Evans WK. The cost of radiotherapy at an Ontario regional cancer centre: a re-evaluation. Crit Rev Oncol Hematol. 1997;32:87-93.

39. Coy P, Schaafsma J, Schofield JA. The cost-effectiveness and costutility of high-dose palliative radiotherapy for advanced non-small-cell lung cancer. Int J Radiat Oncol Biol Phys. 2000;48:1025-33.

40. Evans WK, Will BP, Berthelot J-M, Earle CC. Cost of combined modality interventions for stage III non-small-cell lung cancer. J Clin Oncol. 1997;15:3038-48.

41. Earle CC, Evans WK. Cost-effectiveness of paclitaxel plus cisplatin in advanced non-small-cell lung cancer. Br J Cancer. 1999;80:81520.

42. Sacristan JA, Kennedy-Martin T, Rosell R, et al. Economic evaluation in a randomized phase III clinical trial comparing gemcitabine/cisplatin and etoposide/cisplatin in non-small cell lung cancer. Lung Cancer. 2000;28:97-107.

43. Chen Y-M, Perng R-P, Lee Y-C, et al. Paclitaxel plus carboplatin, compared with paclitaxel plus gemcitabine, shows similar efficacy while more cost-effective: a randomized phase II study of combination chemotherapy against inoperable non-small-cell lung cancer previously untreated. Ann Oncol. 2002;13:108-15.

44. Clegg A, Scott DA, Hewitson P, Sidhu M, Waugh N. Clinical and cost effectiveness of paclitaxel, docetaxel, gemcitabine, and vinorelbine in non-small cell lung cancer: a systematic review. Thorax. 2002;57: 20-8.

45. Lees M, Aristides M, Maniadakis N, McKendrick J, Botwood N, 
Stephenson D. Economic evaluation of gemcitabine alone and in combination with cisplatin in the treatment of nonsmall cell lung cancer. Pharmacoeconomics. 2002;20:325-37.

46. Zieren HU, Muller JM, Hamberger U, Pichlmaier H. Quality of life after surgical therapy of bronchogenic carcinoma. Eur J Cardiothorac Surg. 1996;10:223-7.

47. Mangione CM, Goldman L, Orav EJ, et al. Health-related quality of life after elective surgery. Measurement of longitudinal changes. J Gen Intern Med. 1997;12:686-97.

48. Handy JR Jr, Asaph JW, Skokan L, et al. What happens to patients undergoing lung cancer surgery? Outcomes and quality of life before and after surgery. Chest. 2002;122:21-30.

49. Li WW, Lee TW, Lam SSY, et al. Quality of life following lung cancer resection. Video-assisted thoracic surgery vs thoracotomy. Chest. 2002; 122:584-9.

50. Paul A, Marelli D, Wilson JA, Chiu RC, Mulder DS. Does the surgical trauma of "exploratory thoracotomy" affect survival of patients with bronchogenic carcinoma? Can J Surg. 1989;32:322-7.

51. Takizawa T, Terashima M, Koike T, Akamatsu H, Kurita Y, Yokoyama A. Mediastinal lymph node metastasis in patients with clinical stage I peripheral non-small-cell lung cancer. J Thorac Cardiovasc Surg. 1997;113:248-52.

52. Pettitti D. Meta-analysis, decision analysis, and cost-effectiveness analysis. 2nd ed. New York: Oxford University Press; 2000.

53. Le Chevalier T, IALT Investigators. Results of the Randomized International Adjuvant Lung Cancer Trial (IALT): cisplatin-based chemotherapy (CT) vs no CT in 1867 patients (pts) with resected nonsmall cell lung cancer (NSCLC). Proc Am Soc Clin Oncol. 2003;22:2.

54. Elixhauser A, Halpern M, Schmier J, Luce BR. Health care CBA and CEA from 1991 to 1996: an updated bibliography. Med Care. 1998; 36(Suppl 5):MS1-147.

\section{Discussion}

Dr Douglas J. Mathisen (Boston, Mass). I think you have brought to our attention an important point, albeit a very small point. I think in your article the emphasis on staging can't be stressed enough, and if one does thorough mediastinal staging, this problem ought to be relatively uncommon.

I don't think anybody would argue the notion that if N2 disease is discovered at mediastinoscopy that neoadjuvant therapy clearly has a role to play. I think it's still somewhat of an open question, however. We are all familiar with the 2 series that you presented; they are oftentimes quoted. They are small series with a mixture of patients in them, and therefore the conclusions that they reach, at least the magnitude of the conclusions, I think, can be called into question. The conclusion that you have come to is not necessarily intuitively obvious to the surgeon, and because of that, it causes me to question some of the assumptions upon which this statistical analysis is based, and I would like your thoughts about those.

First and foremost, in the article you mentioned that some of those patients who have neoadjuvant therapy and then surgery included patients who had clinical N2 disease. Clearly that is a factor we all are aware may be spurious, and some of those that are thought to be clinically positive may turn out to be negative. Secondly, at least if I've read the article correctly, of those patients who had surgery and then adjuvant therapy, only $75 \%$ of them went on to adjuvant therapy, and of the ones who went on to adjuvant therapy, only $50 \%$ had chemoradiotherapy. Would it not have been better to examine only those patients who had surgery plus adjuvant therapy? And furthermore, in the group that had neoadjuvant therapy, again, if I read the article correctly, only $70 \%$ had surgery. So shouldn't we have focused on the ones who had neoadjuvant therapy plus surgery? The other assumption that you state upon which many of the conclusions are based has to do with the survival data. As we saw in this slide and as is pointed out in the article, the survival for surgery, plus surgery, plus adjuvant therapy is the same, 1.8 years. Yesterday we heard a presentation on surgery plus adjuvant therapy for single nodes involved where the median survival was 3 years. Based on that kind of a report, does it change your interpretation or at least your sense of the interpretation of this data?

Dr Ferguson (Chicago, Ill). First of all, I would like to comment on the relative importance of this. I agree that clinical staging and pathologic staging, ideally before you get to the thoracotomy, is important. The data I used were from numerous studies that demonstrated no clinical evidence for N2, and in that general type of clinical practice there is about a $15 \%$ incidence of undetected N2 disease. That translates in the United States to at least several thousand people annually.

All of the values that I used to enter into the tree are open for discussion. I'm not trying to mathematically prove anything. Instead, what's been done is a thought experiment. And if others have a different concept about which values are most appropriate to enter in, then they can plug those in and see what the outcomes are. These are just the best estimates that I can come up with from the data and from the literature.

Patients who had neoadjuvant therapy followed by surgery by and large universally had pathologic documentation of N2 disease prior to entering into that treatment program, and so I don't think that there is a potential survival advantage that's very significant in those patients because of clinical evidence for N2 that was not actually pathological N2 disease. You mentioned the possibility of using just patients who receive chemotherapy and radiation therapy in the initial resection group, and, in fact, according to most studies, that would not have affected long-term survival but would have increased the cost of therapy in this group. Thus, the outcome would have swayed even further toward no initial resection. With regards to Steve Keller's presentation yesterday regarding survival in single-station $\mathrm{N} 2$ disease, if I'm not mistaken, that graph represented combined N1 and N2 disease displaying 3-year survival.

Dr Mathisen. Well, what I remember from it, and it's not worth debating, was that the survival for N2 was 36 months. The survival for N1 was close to 60 months.

I have 2 final points. One has to do with the mortality: in the neoadjuvant therapy did it include mortality from the treatment? In other words, was all treatment-related mortality, neoadjuvant therapy plus surgery, included in the figure that came out to be $5 \%$ ? Obviously a slight change in mortality for the 2 groups might influence the ultimate analysis.

Dr Ferguson. Two mortality rates were quoted, one for the initial exploratory operation without resection. The second mortality rate was quoted for patients who had completed neoadjuvant therapy followed by resection. There's a group of patients who did not undergo resection. Their mortality that was associated with the neoadjuvant therapy is included in that nonresection group and their resultant poorer survival.

Dr Mathisen. Finally, having looked at all of this data that you've collected, can you give us some perspective of the issue of single nodal station versus multiple nodal stations for the 2 groups that you looked at? 
Dr Ferguson. Well, I have a personal reflection on it, but I don't have any data that I could use to discuss your question. My sense is that I think we all agree that single-station N2 nodal disease, particularly isolated stations, like level 5, confer much better long-term prognosis, but the ability to confirm the existence of isolated single-station disease, particularly without extracapsular spread, is very limited, particularly at the time of exploratory thoracotomy.

Dr Mathisen. And the final question, if tomorrow you had a patient in whom you did a mediastinoscopy and it was negative, and you explored them; in the course of your routine you did a mediastinal node dissection that you had sent to the pathologist for review and they found a node positive in that patient, prior to going forward, what would you do with that particular patient?

Dr Ferguson. That's when I stop.

Dr Mathisen. Thank you very much.

Dr Frank C. Detterbeck (Chapel Hill, NC). Mark, I also remain a bit skeptical. You assumed that in all the patients who underwent thoracotomy and were found to have a positive node and then closed would actually get neoadjuvant chemotherapy. We know from the experience with giving adjuvant chemotherapy after a resection that we very consistently have a hard time actually delivering that treatment. There are many patients who are noncompliant, drop out, and so forth. There is no published data that actually looks at whether can we deliver neoadjuvant chemoradiotherapy after an exploratory thoracotomy. However, I'm skeptical that you can do so in all of the patients, and I think that would color your conclusions.

Dr Ferguson. The point is well taken. It reflects a little bit about the initial quote that I presented and that the morbidity and mortality of the thoracotomy has already been incurred, with which I disagree. The morbidity and mortality should be substantially less. And I think the likelihood of those patients going to neoadjuvant chemotherapy should be substantially higher than the percentage of patients who ultimately get adjuvant postoperative therapy after a formal lung resection. But that perspective was not entered into the model, you're correct. 